Dampak Akreditasi Rumah Sakit: Studi Kualitatif Terhadap Perawat Di RSUD KRT Setjonegoro Wonosobo

\author{
Murti Mandawati ${ }^{1}$, Muhammad Jauhar Fu'adi ${ }^{2}$ Jaelan $^{3}$ \\ ${ }^{1}$ Balai Pelatihan Kesehatan Provinsi Jawa Tengah \\ ${ }^{2}$ Balai Kesehatan Masyarakat Wilayah Pati \\ ${ }^{3}$ Dinas Kesehatan Kabupaten Wonosobo
}

NURSCOPE

Jurnal Keperawatan dan Pemikiran IImiah Mandawati,M (2018). Dampak Akreditasi Rumah Sakit: Studi Kualitatif Terhadap Perawat Di RSUD KRT Setjonegoro Wonosobo. Nurscope.Jurnal KeperawatanPemikiranIlmiah. 4 (4). 23-29

\begin{abstract}
Abstrak
Pendahuluan: Kementerian kesehatan menyatakan akreditasi adalah langkah untuk menjamin rumah sakit agar mengutamakan pelayanan, keselamatan dan perlindungan masyarakat, sehingga akreditasi wajib bagi pelayanan kesehatan. Asuhan keperawatan merupakan salah satu pelayanan yang paling banyak dinilai dalam akreditasi. Bagaimana persepsi perawat mengenai akreditasi menjadi pertanyaan penelitian ini. Metodologi: Penelitian kualitatif ini melibatkan 21 perawat rumah sakit. Pedoman wawancara diginakanuntuk mengumpulkan data. Selanjutnya data dianalisis dengan analisis isi sehingga ditemukan tema. Hasil: Responden meyatakan akreditasi penting dilaksanakan. Dampak positif akreditasi adalah peningkatan kepedulian perawat pada indikator keselamatan pasien, yaitu pebaikan pada alur pelaporan masalah, kepatuhan terhadap standar operasional prosedur, komunikasi antar pertugas kesehatan, pendokumentasian, fasilitas pelayanan, pendidikan kesehatan, lingkungan kerja dan adanya pendidikan berkelanjutan. Diskusi: pandangan positif terhadap kegiatan akreditas menjadi awal yang baik bagi rumah sakit untuk melanjutkan langkah perbaikan kualitas pelayanan. Karena hal utama dalam pelayanan adalah kualitas pelayanan yang dinilai dari indikator klinis pelayanan, bukan kelengkapan dokumentasi.
\end{abstract}

Keywords: akreditasi, perawat, persepsi, rumah sakit

\title{
Impact Of Hospital Acreditation: Qualitative Study To Nurses In RSUD KRT Setjonegoro Of Wonosobo
}

\begin{abstract}
Introduction: As stated by the Ministry of Health, hospital accreditation is mandatory done through a series of assessments and improvements as a step to ensure the hospital in prioritizing public services, safety and protection. Nursing care as one of the main services in hospitals is the most widely rated service in accreditation. Therefore, this study was done to determine the nurse's perception of the impact of accreditation on nursing. Methodology: This qualitative study examined 21 hospital nurses as its respondents. The data were collected by in-depth interviews using interview guides. The data were then analyzed and categorized to determine the theme. Results: According to the nurses, hospital accreditation was important to implement. The positive impacts of accreditation were the increased care of nurses on patient safety indicators, among others, improvements in the problem reporting flow, compliance with standard operating procedures, communication among health workers, documentation, service facilities, continuing nurses education, health education, and working enviroument. Discussion: a positive outlook on accreditation activities is a good start for hospitals to continue to improve service quality. Because the main thing in service is the quality of service assessed from the clinical indicators of the service, not the completeness of the documentation.
\end{abstract}

Keywords: accreditation, hospital, nurse, perception

Corresponding Author:

Penulis $^{1}$, Bapelkes Prov Jateng, Jln. Wilis No 1, Wero, Gombong, Kebumen Kotak Pos 111, Kode

Pos 54416. e-mail: murti_mandawati@yahoo.com 


\section{PENDAHULUAN}

Salah satu upaya pemerintah untuk mendorong agar rumah sakit mengutamakan pelayanan, keselamatan dan perlindungan kepada masyarakat adalah dengan mewajibkan rumah sakit untuk melakukan akreditasi (Permenkes 012 th 2012). Menurut Permenkes 012 tahun 2012, akreditasi adalah pengakuan yang diberikan kepada rumah sakit karena telah berupaya meningkatkan mutu pelayanan secara berkesinambungan. Pengakuan ini diberikan oleh lembaga independen yang bertugas melakukan akreditasi dan sudah memperoleh pengakuan dari Menteri Kesehatan. Lembaga independen yang bertugas melakukan akreditasi terhadap rumah sakit di Indonesia adalah Komisi Akreditasi Rumah sakit (KARS).

Menurut Lumenta (2003) akreditasi sangat berkaitan erat dengan mutu pelayanan yang diberikan rumah sakit. Artinya jika akreditasi dilakukan dengan baik, maka akan terjadi peningkatan mutu pelayanan rumah sakit. Namun menurut Pangestuti, Kuntjoro dan Utarini (2002) hasil akreditasi tidak otomatis meningkatkan kualitas pelayanan rumah sakit. Hal tersebut karena akreditasi pelayanan kesehatan di Indonesia belum menilai indikator klinis pelayanan kesehatan (Soepojo, Kuntjoro, dan Utarini, 2002). Pertanyaan mengenai efikasi akreditasi terhadap mutu layanan pasien dan tingkat kesembuhan pasien juga dilontarkan beberapa ahli di luar negeri ( Hinchcliff, Greenfield, dan Moldovan, 2012).

Meskipun demikian, adanya kewajiban untuk melakukan akreditasi terhadap pelayanan yang diberikan mendorong hampir semua rumah sakit untuk melaksanakan program tersebut, apalagi pemerintah juga memberikan kewajiban kepada pemerintah pusat dan daerah untuk mendukung rumah sakit yang ada di daerahnya ketika melakukan akreditasi. Kementerian kesehatan menargetkan pada tahun 2014 seluruh rumah sakit di Indonesia sudah terakreditasi, minimal terakreditasi nasional, tetapi hingga tahun 2016 baru 284 (11,3\%) rumah sakit yang terakreditasi di Indonesia. ( Yankes, 2016).

Bagaimana pendapat perawat mengenai dampak akreditasi terhadap pelayanan keperawatan belum banyak diketahui. Oleh karena itu, penelitian ini akan mengungkap pendapat dan sudut pandang perawat mengenai dampak akreditasi terhadap pelayanan perawat yang diberikan kepada pasien.

\section{METODE}

Penelitian ini adalah penelitian kualitatif, dilaksanakan pada Juni sampai dengan Agustus $2016 \mathrm{di}$ RSUD Setjonegoro Wonosobo. Data dikumpulkan dengan wawancara mendalam terhadap 21 orang perawat yang mewakili semua unit pelayanan di RSUD Setjonegoro. Wawancara mendalam dilakukan dengan mengunakan pedoman wawancara yang disusun berdasar studi literatur. Selanjutnya analisis data dilakukan dengan menggunakan analisis isi. Hasil wawancara dibuat kategorisasi selanjutnya dibuat tema.

\section{HASIL}

Jumlah responden adalah 21 perawat dengan tingkat pendidikan D3 sampai dengan S1 Profesi. Berdasar jenis kelamin ada 8 orang laki-laki dan 13 orang perempuan. Lebih jelasnya pada Tabel 1.

Tabel 1. Responden berdasar tingkat pendidikan

\begin{tabular}{llll}
\hline Jenis kelamin & \multicolumn{3}{c}{ Tingkat Pendidikan } \\
\hline & D3 Kept & D3 Kept gigi & S1 Kept Ns \\
\hline Laki-laki & 4 orang & 1orang & 3 orang \\
\hline Perempuan & 5 orang & - & 8 orang \\
\hline
\end{tabular}


Responden berasal dari manajer keperawatan sebanyak 3 orang, dan 19 orang adalah perawat pelaksana. Perawa yang bertugas di rawat inap 3 orang, Ruang Hemodialisis 3 orang, UGD 2 orang dan sisanya 11 orang adalah perawat rawat jalan. Rerata usia responden adalah 32 tahun dan rerata lama bekerja adalah 6 tahun. Semua responden pernah bekerja sebagai perawat pelaksana.

Analisis data menunjukkan bahwa secara umum semua responden menyatakan bahwa akreditasi memiliki manfaat dan setuju sampai sangat setuju dengan pelaksanaan akreditasi. Hal ini tercermin dari salah satu pendapat responden berikut ini:

"Excited dengan akreditasi rumah sakit karena orang biasanya kerja standar, jadi ketika ngomong mutu, maka mutu harus pakai standar. Karena akreditasi instrumeninsrumennya mengukur mutu." (R1)

Responden menyatakan bahwa alasan menyetujui adanya kareditasi adalah adanya banyak dampak positif dalam akreditasi antara lain: lebih tertatanya pengelolaan rumah sakit. Dan perubahan cara pengambilan keputusan oleh pimpinan. Semua pegawai menjadi tahu indikator apa yang harus diperhatikan dalam pelayanan, cara pelaporan masalah, dan keputusan berdasar aspirasi dari bawahan.

Dampak akreditasi menurut responden adalah:

a. Manajemen membaik

Adanya dokumentasi, maka alur komunikasi dan alur pelaporan menjadi lebih baik. Sehingga jika ada masalah perawat menajdi tahu kemana harus menyelesaikan masalah tersebut. Hal ini daat diketahui dari pendapat salah sat responden berikut ini:

"Pendokumentasian ada alur yang lebih tertata lagi, misalnya kalau mau rawat inap alurnya lebih jelas. Ada SOP nya kalau mau rawat inap harus ada ini - ini ... ada panduannya ." (R17)

"kita tau lewat pintu mana kita harus bicara. Jadi jalur komunikasi nya jelas" (R3)

Akreditasi di Indonesia identik dengan pendokumentasian dan kelengkapan administrasi dari kegiatan tersebut perawat-perawat menjadi belajar semua proses kegiatan pelayanan keperawatan.

b. Bekerja sesuai standar

Dengan akreditasi perawat bekerja sesuai dengan standar operasional Sehingga perawat merasa aman selama bekerja. Hal ini sesuai dengan pendapat responden berikut ini:

"Perawat menjadi lebih tenang karena sudah bekerja sesuai dengan standar dan tata kerja yang jelas. Tinggal taat tidak dengan SPO. Sekarang perawat akan merujuk ke SPO kalau bekerja. Bahkan mereka memberi masukan terhadap SPO yang ada" (R21)

"Kalau melakukan apapun jadi jelas karena melakukan sesuai standar. " (R3)

Akreditasi mendorong perawat untuk membuka kembali standar operasional prosedur yang selama inihanya sebagai dokumentasi. Semua kegiatan keperawatan ada SOP yang harus ditaati. Hal ini sesuai dengan prinsip keselamatan pasien, bahwa semua pasien harus diayani sesuai SOP.

c. Pencegahan infeksi dan keselamatan pasien menjadi prioritas 
Akreditasi menjadikan cuci tangan menjadi bagian dari pencegahan infeksi yang sangat ditekankan, selain itu keselamatan pasien juga menjadi prioritas. Pencegahan infeksi dan menjaga keselaman pasien ini antara lain adalah dengan cuci tangan, pemasangan identitas pasien, pencegahan jatuh. Hal ini dapat diketahui dari pendapat responden berikut ini:

"ada panduannya. Pencegahan infeksi sekarang ada handscrub, dulu cuci tangan."(R17)

"Penanganan pencegahan risiko jatuh mulai dari identifikasi sampai penanganannya ada semua. Kita jadi tahu. Karena ada pelatihannya. Penatalaksanaan obat terkait alergi, peneahan Infeksi dan hygiene. Lebih ditekankan. Dan keamanan dan keselamatan pasien. penatalaksanaan pasien sama, tapi ada perubahan sedkit, misal cuci tangan, penanganan sampah digolong-golongkan ada ampul, jarum."(R13)

d. Meningkatkan Komunikasi dan dokumentasi lebih lengkap

Salah satu format dokumentasi pelayanan pasien yang baru bagi perawat RSUD KRT Setjonegoro adalah adanya dokumentasi terintegrasi semua tenaga medis yag merawat pasien. Format ini menjadikan perawat, dokter, nutrisionist, fisioterapist, dll menuliskan analisis dan intervensinya dalam satu format dan mendorong atara petugaskesehatan membaca apa yang terjadi pada pasie dan penatalaksanaan apa yang sudah diberikan.

"Sekarang masalah dokumentasi jadi satu lembar, jadi kita bisa membaca tulisan semua profesi. Adanya form CPPT ini jelas kita bisa membaca tulisan-tulisan orang lain".(R3)

“Dmpak positif jadi tahu ini yang sesuai standar, ini yang tidak sesuai dengan standar. Discharge palnning, pendkes, pasien safety semua ada pendokumentasiannya.

Transfer pasien kita ada pendokumentasian, dulu tidak ada." (R11)

e. Fasilitas meningkat

Akreditasi mendorong rumah sakit untuk memperbaii dan melengkapi faslitas pelayanan kesehatan sesuai denga standar yang diberikan oleh borang akreditasi. Seperti pendapat responden berikut ini.

" semakin membenahi, meningkatkan mutu, proses sterilnya lebih ketat lagi. Dan itu masih kontinyu samai sekarang karena ada PPI. Peningkatan sarana dan prasarana. Sekaang ada sistem yang baru. Alat dari laborat langsung bisa kirim hasil ke ruangan." (R15)

f. Pendidikan kesehatan kepada pasien lebih baik

Pasien menjadi prioritas utama, pasien mendapat informasi dari mulai pintu pendaftaran sampai saat dirawat. Mulai dari atata cara mendaftar sampai dengan cara memberikan asuhan kepada keluarga. Kadang pendidikan apsien ini menjadi sangatmenyita waktu bagi perawat karena tingkat pendidikan dan pengetahun pasien yang bermacam-macam. Hal tersebut seperti terungkap dalam wawancara berikut ini:

“Perawat akan memberikan edukasi misalnya tentang cuci tangan ke keluarga dan pasien" (R15)

“Perawat menjadi labih care. karena pasien masuk kita kaji, salah satu anggota keluarga juga kita wawancarai di depan. sampai punya anak berapa kerja dimana kita tahu.... sampai kita serasa menjadidekat dengan pasien" (R6) 
Dampak lainnya adalah meningkatkan kebersamaan dan udara RS menajdi lebih segar. Hal ini dapat terlihat dalam pernyataan responden berikut ini.

"Lebih seger, karena sekarang merokok di Rs tidak boleh dan ada tim anti rokok. Jadi udara RS jadi lebih seger.... Gathering seluruh civitas hospitalia." (R16)

Perawat menjadi tahu banyak karena ada inhouse training sehingga mendapat banyak pengetahuan. Seperti cntoh pernyataan berikut ini.

“Penanganan pencegahan risiko jatuh mulai dari identifikasi sampai penanganannya ada semua. Kita jadi tahu. Karena ada pelatihannya. Penatalaksanaan obat terkait alergi, peneahan Infeksi dan hygiene. Lebih ditekankan." (R13)

Selain dampak positif akreditasi ada juga dampak negatifnya, yaitu

a. Menyita waktu dan tenaga

Akreditasi menyebabkan penggunaan waktu lebih banyak untuk urusan admnistrasi. Seperti contoh pendapat perawat berikut ini.

"Banyak sekali yang ahrus dilengkapi. Sehingga waktunya tersita untuk melengkapi dokmen itu. Untuk mengisi juga butuh waktu. Tapi semua itu tujuannya untuk memenuhi standar." (R20)

Selain itu dengan akreditasi menyebabkan perawat harus memberikan pendidikan dan informasi kepada pasien dan keluarga lebih lama. Sebagaimana pendapat responden berikut ini.

:"Menerima pasien sekrang harus 2 perawat, satu ngajari pasien,pelayanan misalnya penangaan nyeri, penggunaan siderail, satunya ngajari keluarga cuci tangan dengan paai air dan handscrub. Itu kan menghabiskan waktu. KAlau keluarganya paham cepet, kalau SDMnya kurang ya hehehehe....kalau masih muda dan pendidikannnya cukup enak, sampai jam kunjung harus kita ulangi juga kan dari pendaftaran. Tapi kalau keluarga sudah sepuh wahuh hehehe" (R18)

b. Dokumentasi menjadi lebih banyak

Akreditasi menyebabkan perawat harus melakukan dokumentasi yang lebih banyak. Sebagaimana termakstub dalam salah satu pendapat responden berikut ini:

"kita menjadi banyak tulis menulis. Dokuementasi nya jadi banyak.tangannya capek".(R6)

Akreditasi menyebabkan peningkatan biaya yang harus dikeluarkan rumah sakit. Hal ini dapat terlihat dari responden berikut ini.

"Lelah, kedua butuh waktu lebih lama karena harus sesuai prosedur. Dari awal pasien datang kita harus memberikan pelayanan sesuai prosedur. Pembiayaan lebih banyak, cntohnya assessment, kertas-kertas yang dipersiapkan lebih banyak." (R14)

\section{PEMBAHASAN}

Temuan dalam penelitian ini menunjukkan bahwa perawat memiliki persepsi positif terhadap pelaksanaan akreditasi rumah sakit. Perawat berpendapat bahwa akreditasi mendorong perawat untuk lebih memperhatikan upaya keselamatan pasien di rumah sakit, diantaranya penerapan standar opeasional prosedur yang lebih baik dalam upaya pencegahan infeksi, mobilisasi pasien, dan asuhan keperawatan. Selain itu akreditasi juga mendorong perawat melakukan pendokumentasian secara lengkap, mendorong perawat melakukan pendidikan kesehatan kepada 
pasien dan keluarga secara intensif serta mendorong dokumentasi yang terintegrasi sehingga menimbulkan komunikasi antar tim kesehatan yang merawat pasien. Adanya komunikasi yang baik antar petugas medis ini sangat bermanfaat dalam pelayanan keperawatan, karena beberapa penelitian menunjukkan bahwa komunikasi perawat dengan dokter beum cukup baik dan akibat dari hal ini adalah pelayanan kepasien menjadi tidak optimal.

Akibat persepsi bahwa akreditasi rumah sakit di Indonesia sangat bersih adalah adanya perbaikan fasilitas dan lingkungan rumah sakit. Hal ini tercermin dalam hasl wawancara perawat yang menyatakan bahwa dengan akreditasi fasilitas menjadi lebih lengkap dan aturan kawasan bebas merokok di rumah sakit benar-benar diterapkan.

Selain persepsi potif terhadap akreditasi, perawat di RSUD Setjonegoro dalam penelitian ini juga menganggap akreditai sebagai ujian yang harus dihadapi untuk mendapatkan sertifikat pengakuan. Pesepsi akreditasi sebagai ujian karena akreditasi rumah sakit di Indonesia masih bersifat menilai belum membina. Tim asesor akreditasi akan datang 3 hari untuk menilai dokumen, kemudian mendatangi petugas kesehatan yang sedang bertugas. Adapun pembinaan terhadap rumah sakit diserahkan kepada Dinas Kesehatan Provinsi dalam hal ini Dinas Kesehatan Provinsi Jawa Tengah. Hal ini sangat berbeda dengan akreditasi yang dilakukan di Australia yang menggunakan akreditasi sebagai sarana pembinaan rumah sakit (Soepojo, Kuntjoro dan Utarini, 2002).

Perawat memiliki persepsi positif terhadap akreditasi, disamping itu perawat juga berharap agar semangat akreditasi ini tidak hanya selesai dengan selesainya penilaian. Persepsi positif ini sebaiknya dimanfaatkan sebaik-baiknya oleh pimpinan rumah sakit untuk memperbaiki pelayanan secara berkelanjutan. Semngat ini dapat dijadikan modal untuk meningkatkan pelayanan dengan penilian kualitas indikator klinis pelayanan sehingga pasien akan benar-benar merasakan perbedaan pelayanan yang diberikan rumah sakit.

\section{SIMPULAN DAN SARAN}

Simpulan

penelitian ini menunjukkan bahwa perawat memiliki persepsi posiif terhadap pelaksanaan akreditasi di RSUD Setjonegoro Wonosobo. Dampak positif dari pelaksanaan akreditasi bagi pelayanan keperawatan adalah meningkatnya usaha keselamatan pasien yag dilakukan oleh perawat. Selain itu akreditasi juga memberikan dampak pada perbaikan fasilitas dan lingkungan kerja.

Saran

Saran untuk penelitian selanjutnya adalah menilai dampak akreditasi terhadap mutu pelayanan klinis perawat.

\section{KEPUSTAKAAN}

Akhenizan A, Shaw C, The Attitude of health care professionals toward accreditation: A systematic review of literature. J Family Community Med. 2012; 19:74-80

Bagian Humas Sekretariat Direktorat Jenderal Bina Upaya Kesehatan Kementerian Kesehatan RI. Jumlah surveyor akreditasi rumah sakit terus ditambah. 19 Februari 2016. Diakses tanggal 29 Juni 2016 di http://print.kompas.com/baca/2015/05/12/Jumlah-Surveyor-untukAkreditasi-Rumah-Sakit-Terus 
El-Jardali F, Jamal D, Dimassi H, Ammar W, dan Tchaghchaghian. The impact of hospital accreditation on quality of care: perception of Lebanese nurse. 2008. International Journal of quality of in health care. 20(5);363-371

Ho M, Chang H, Chiu Y, dan Norris J.L. Effects of hospital accreditation on Medical students: A national qualitative study in Taiwan. 2014. Academic Medicine. Vol 89; 11

Kementerian Kesehatan. Permenkes No 012 tahun 2012 tentang Akreditasi rumah sakit. 2012. Warta perundang-undangan

Komisi Akreditasi Rumah sakit (KARS). Instrumen Akreditasi rumah sakit standar akreditasi versi 2012 edisi 1. 2012. Komisi Akreditasi RUmah Sakit. Di akses tanggal 29 Juni 2016. Di Instrumen_akreditasi_rs_final_Des_2012pdf

Lumenta N. Akreditasi rumah sakit di luar negeri. Makalah dalam pelatihan akreditasi RS di Dinkes Provinsi DKI Jakarta: 30-31 Oktober 2003

Manzo, B.F. Nursing in hospital accreditation process: practice and implication in the work quotidian, Rev. Latino-Am.emfermagem. 2012. Jan-Feb; 20(1)151:8

Poerwani S.K., dan Sopacua E. Akreditasi sebagai upaya peningkatan mutu pelayanan rumah sakit. 2006. Buletin Penelitian Sistem Kesehatan. 9(3); 125-133

Pomey M.P, Contrandiopolous A.P., Francois P, dan Bertrand D. Accreditation A tool for organizational change in hospital. International Journal Health care qual Assur Inc Leadrsh Health serv. 2004; 17:113-124

Soepojo $\mathrm{P}$, Koentjoro $\mathrm{T}$, dan Utarini A. Bechmarking system akreditasi rumah sakit di Indonesia dan Australia. 2002. Jurnal Manajemen pelayanan Kesehatan, 2.

Stolewinder J. A study of doctors' view on how hospital accreditation can assist them provide quality and safe care to consumers. Melbourne, Australia: Monash University, departemen of epidemiology and Preventive Medicine, 2004

Wocher J.C. Effects of international accreditation on patient care in Japanese hospital: nurses' perspective. 2012. Diakses tanggal 12 Juli 2016 di www.jointcommissioninternational.org/assets/3/7/JCl-News-Kameda-Report.pdf 